\title{
Touch Screen Tester Device End-Effector
}

\author{
STEFAN ADRIAN TIMPEA*, CRISTIAN COSMA2*, DANUT SOSDEAN² \\ ${ }^{1}$ Continental Automotive Timisoara, 1 Siemens Str., 300724, Timisoara, Romania \\ 2Politehnica University Timisoara, Department of Material and Manufacturing Engineering, 1 Mihai Viteazu Blvd., 300222, Timisoara, \\ Romania
}

\begin{abstract}
The paper describes the implementation of a new type of End-effector for testing touch screen devices. To automate the testing process of touch screens devices, a new type of end-effector is presented. The Endeffector can be attached at diferent tipes of robotics sistem trough a connection part, which can be designed depending on the type of robot. For the movements in the test scenario, the end-effector is designed to move like a human hand. To create the physical parts in the prototype phase is used an field of rapid prototyping (RP) technology, called fused deposition modeling (FDM).
\end{abstract}

Key words: touch screen testing platform, end effector, solenoid, Acrylonitrile-Butadiene-Styrene, fused deposition modeling

The end-effector can be used to perform repeatable testing of an electronic touch screen device, such as a telecommunication device that includes a touch screen display [1, 2]. Operations in the test phase can include initiating voice calls, sending and receiving data (messages, videos, music, and so on), running applications and performing other tasks [3].

Running test scenarios, electronic devices can be tested in a laboratory environment using an automated process, making the tests relatively inexpensive and repeatable. The end-effector may contain different types of tips to engage the touch screen device.

The electronics industry is a large industry where new products are continuously released and implemented to be used by people and companies, especially when using specialized software [4,5]. Many new products include touch screens which allow the user to enter commands by touching the device screen, instead of relying on traditional inputs such as buttons.

Before a product is launched on the market, it is often tested to ensure it's fully functional. Testing the device may be used to measure durability, battery performance, application performance, screen sensitivity or other quantifiable aspects of the operation of the tested electronic device.

\section{Touch screen technology}

Touch screen technology is divided into two big categories, capacitive and resistive 6-8].

The end effector can be used to test capacitive and resistive screens [1-2]. Everything depends on the power of the solenoid.

Short description of each technology:

\section{Capacitive Technology}

A capacitive touch screen panel is coated with a material that stores electrical charges. The capacitive systems can transmit up to $90 \%$ of light from the monitor. It is divided into two categories. In Surface-capacitive technology only one side of the insulator is coated with a conducting layer.

Whenever a human finger touches the screen, figure 1 [9], conduction of electric charges occurs over the uncoated layer which results in the formation of dynamic capacitor. The controller then detects the position of touch by measuring the change in capacitance at the four corners of the screen.

In projected capacitive technology, the conductive layer (Indium Tin Oxide) is etched to form a grid of multiple horizontal and vertical electrodes. Itinvolves sensing along both the $X$ and $Y$ axis using clearly etched ITO pattern. For increasing the accuracy of the system, the projective screen contains a sensor at every interaction of the row and column.

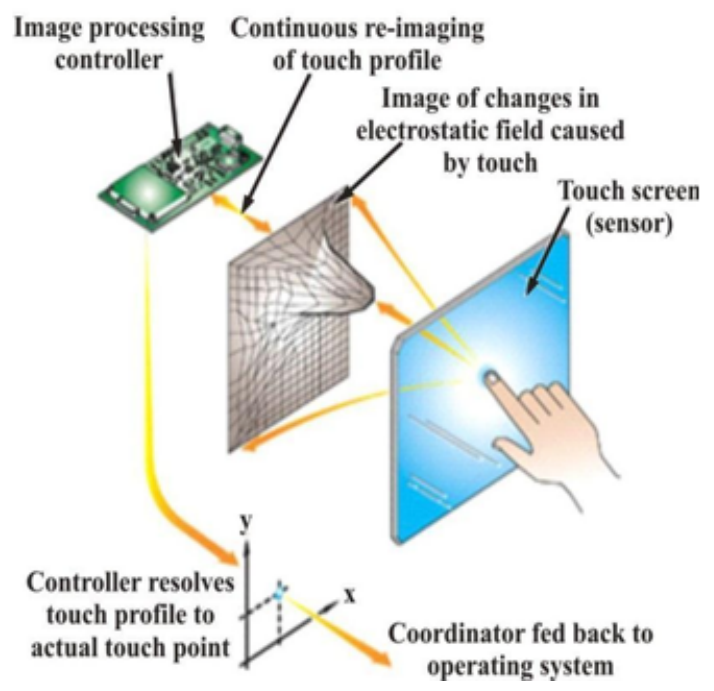

Fig. 1. Capacitive touch-screen [9]

Resistive technology

Resistive touch screen technology consists of a glass or acrylic panel that is coated with electrically conductive and resistive layers. The thin layers are separated by invisible separator dots. When operating, an electrical current moves through the screen. When pressure is applied to the screen figure 2 [10] the layers are pressed together, causing a change in the electrical current and a touch is registered. 


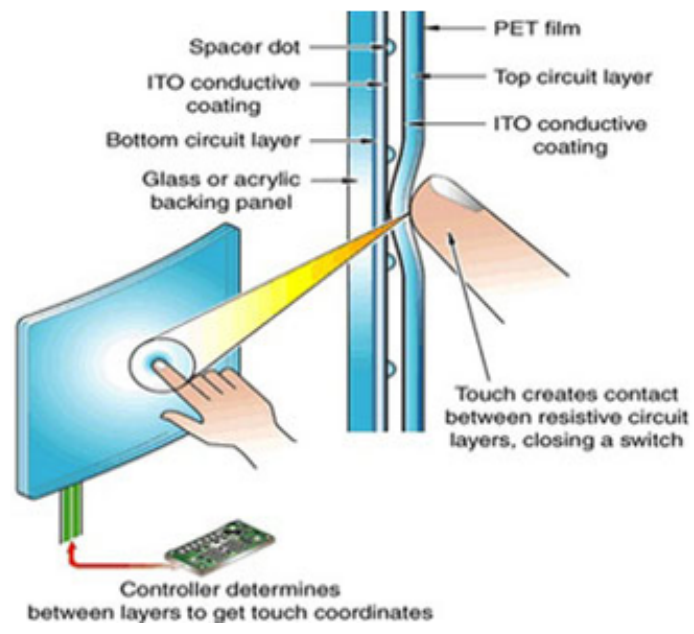

Fig. 2. Resistive touch-screen [10]

\section{Experimental part}

\section{Marketing rsearch}

In the following, a brief description of the existing end effectors on the market will be made. For a better understanding of this technology it was necessary a market study to see the existing models.

The following models had been found:

-TakTouch 1000 - by Tactile Automation Inc. Cartesian robot, tool storage with different end effectors [2]. Each end effectors are designed to take up a certain function.

-SR Scara Pro by Sastra Robotics. SCARA robot. End effector with one finger. The end effector is designed with a single finger, a limited number of features.

-IQ MATT by Rinf Tech. DELTA robot. End effector with tree fingers. They have built a prototype; The $Z$ axis translation is made by the robot.

For end effector 1 a system has been found that incorporates most of the operations in one product.

For platform 2 a system has been found that brings a variety of operations attached to the SCARA robot.

For platform 2 for finger tapping function has been found the solenoid solution (fast tapping, movement on the $Z$ axis).

\section{Description of the END-EFFECTOR}

In robotics, an end effector is the device at the end of a robotic arm, designed to interact with the environment.

The End-effector can be attached to various types of robots such as SCARA, CARTESIAN, DELTA etc. Depending on which robots are used, a connection part may be designed to attach the End-effector.

Overall dimensions are $160 \times 100 \times 85 \mathrm{~mm}$ and the working area for the fingers when extended, results in a circle with a maximum diameter of $68 \mathrm{~mm}$.

In figure 3 an exploded view of the End-effector with the following parts and subassemblies is shown:

- On the base plate 4 there are mounted and centered the subassemblies 3 which contains the precision linear guides and two types of racks.

- On the racks there is a centering hole where the finger 5,6,7 subassemblies are centered and fixed.

- The finger assembly consists of a support in which the solenoid is centered and fixed, through the solenoid the movement on $\mathrm{Z}$ axis is made and the finger tips have a special rubber which engages the touch screen.

- The next subassembly, 2, is centered and fixed on the base plate 4 and consists of a support for the two stepper motors. These two large subanssemblies allow movement on the $X$ and $Y$ axis of the subassembly described above through the rack pinion system.
- In the subassembly 8 it's presented the micro limit switch, when the finger no. 6 touched the limit switch an input goes to the robot and the point XOYOZO it's found.

- The final part of the final effector is the upper housing which is centered and fixed on the base plate.

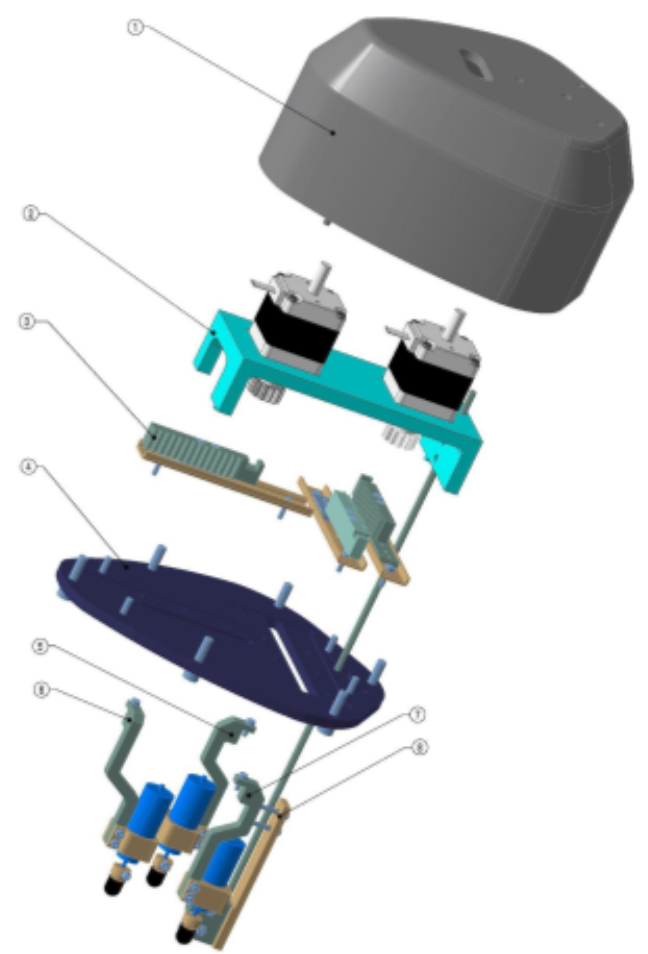

Fig.3. Exploded View of the End-effector

\section{$Z$ axis translation}

The $Z$ axis translation is made in the final effector because we need a high repeatability on the fingers, resulting a lower moment of inertia at the robot arm. The $Z$ axis translation is made trough the solenoid (fig. 4)

Solenoid is an electromechanical device made up of a coil which produces a magnetic field when electric current is passed through it. In some applications, the coil surrounds an iron plunger which becomes magnetized and moves in one direction upon application of current.

When the flow of current is reversed, the plunger moves in the opposite direction.

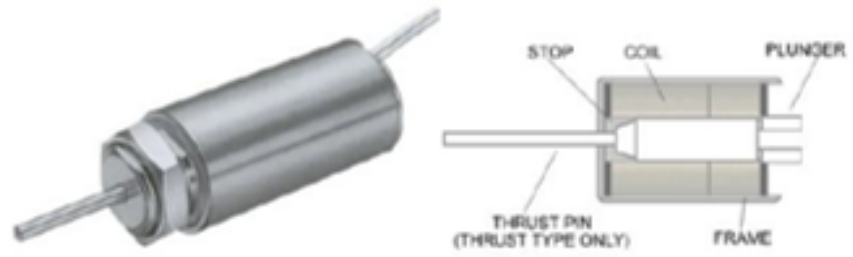

Fig 4. Solenoid

\section{Working types of the End-effector}

The working types of the end effector are shown in figure 5 [7] and can be interpreted as following:

Tap: By lifting the two fingers, the third can act by making a soft hit on the touch screen, eg turning on / off an application.

Press: By lifting the two fingers, the third can act by making a long push, eg starting an application's menu.

Tapping with multiple fingers: The touchscreen can be engaged by the action of two / three fingers, eg drawing two or three parallel lines.

Pinch and Spread: By lifting a finger, the two fingers engage the touch screen and can zoom out a picture, eg zoom out to see in detail. 
And many more by combining them.

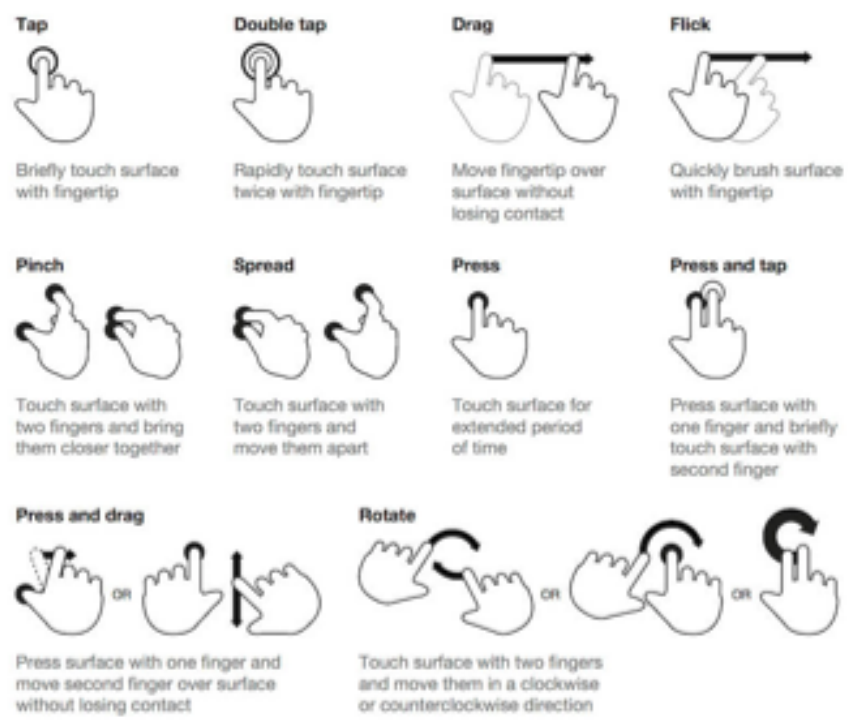

Fig. 5. Working movements [7]

Manufacture of the end-effector components and assembly in the prototype phase

To create the physical parts in the prototype phase is used an field of rapid prototyping (RP) [11] technology, called fused deposition modeling (FDM) [12-17] .

In RP, the term rapid is relative, it aims at the automated step from CAD data to machine, rather than at the speed of the techniques. Depending on the dimensions of the object, production times can be as a few days, especially with complex parts or when long cooling times are required. The manufacturing process is slow, butcompared to traditional production techniques it can provide the physical parts in a very short time [12, 13]. This relatively fast production allows analyzing parts in a very early stage of designing, which decreases the resulting design cost [18].

FDM is a process for making a solid three-dimensional object with almost any shape from a digital model. The traditional techniques to optain the physical object are based on the removal of the material by methods as milling, while the layers of molten material are positioned successively, so the object is built layer by layer until it reaches the final shape. In this way RP is justified for prototype production.

The extrusion method functions under the following principle: the extrusion material (filament input) is brought into a semi-solid state and forced through a nozzle to form a filament with a narrower diameter than the diameter of the input filament that will rapidly solidify after the extrusion (fig. 6) [19, 20].

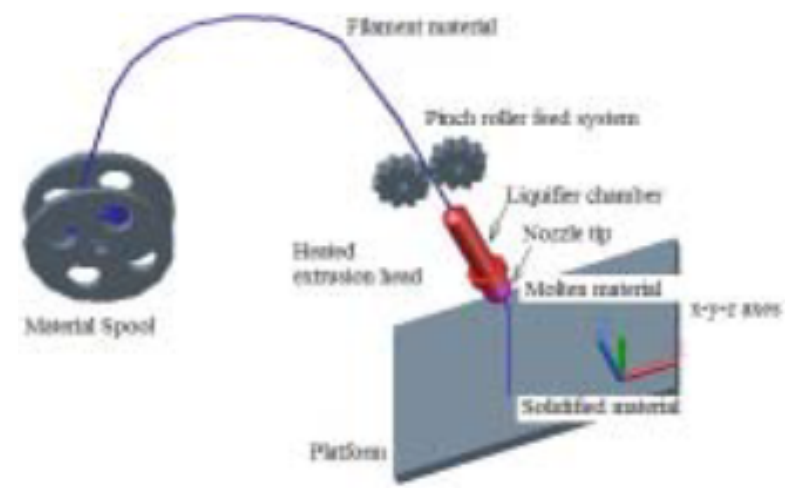

Fig. 6. Schematic of Extrusion-Based Systems [4]
Printing filaments used to be limited to ABS (AcrylonitrileButadiene-Styrene), but today there is a wide range of different materials on the market.

Before extrusion, the filament must be free of moisture. General conditions for extrusion require the heating of the ABS filament at a temperature range of $215-260^{\circ} \mathrm{C}$ and the table where the extruded part is positioned at a temperature range of $90-115^{\circ} \mathrm{C}$.

Extrusion temperature in the experimental parts was $260^{\circ} \mathrm{C}$, no rafts were used, while the extrusion speed was kept at $40 \mathrm{~mm} / \mathrm{s}$. The technical characteristics of filaments used in experimental research are: filament diameter 2.85 $\mathrm{mm}$ and filament diameter after extrusion $0.3 \mathrm{~mm}$. Because this type of printing process requires a heated base, printing baseplate temperature was set to $115^{\circ} \mathrm{C}$. ABS can be used for full functional models [19].

Additive manufacturing requires details on the basic dimensions of the piece, on understanding how the 3D printer works, the construction method of physical piece and the materials that are used in the process.

The technological process of manufacturing FDM is briefly described in figure 7 [21].

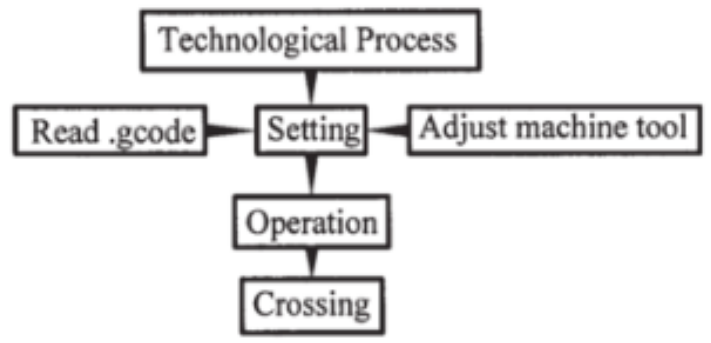

Fig. 7. Technological process of the fused deposition modeling (FDM)

Table 1 shows the characteristics of the FDM process used for all manufactured parts [22].

Table 1

CARACTERISTICS OF THE FDM PROCESS

\begin{tabular}{|l|c|}
\hline Parameter & ABS \\
\hline Nozzle & $0.3[\mathrm{~mm}]$ \\
\hline Layer Height & $0.1[\mathrm{~mm}]$ \\
\hline Profile & Normal \\
\hline Wall Thickness & $1[\mathrm{~mm}]$ \\
\hline Top/Bottom Thickness & $0.8[\mathrm{~mm}]$ \\
\hline Infill Densit & $100 \%$ \\
\hline Print Speed & $40[\mathrm{~mm} / \mathrm{s}]$ \\
\hline Travel Speed & $100[\mathrm{~mm} / \mathrm{s}]$ \\
\hline Support Placement & Everywhare \\
\hline $\begin{array}{l}\text { Build Plate Adhesion } \\
\text { Tpe }\end{array}$ & Skirt \\
\hline
\end{tabular}

ABS(Acrylonitrile-Butadiene-Styrene) filament was used to build the physical parts in the experimental part of this article ( fig 8).

\section{Assembly the End-effector in the prototype phase}

In the figure 9. is presented the End-effector in the prototype phase.

\section{Simulation the pushing force}

The most pressed area of the touch screen is in the finger tapping area during the test scenario figure 10.

A force of $1.2[\mathrm{~N}]$ is exerted on the touch screen, this value being determined by the solenoid pushing force introduced into the CAD program, the critical value when 


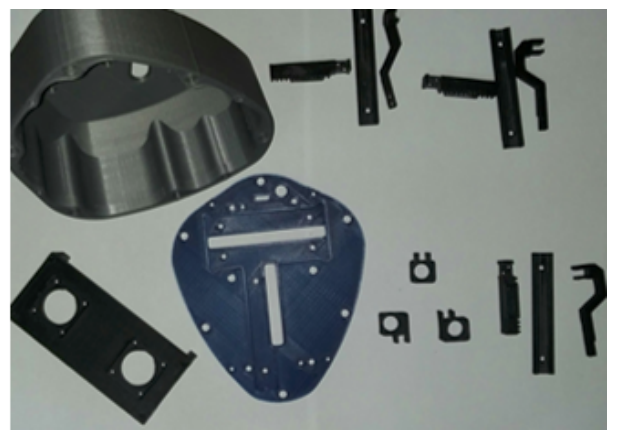

Fig. 8. End effector physical parts

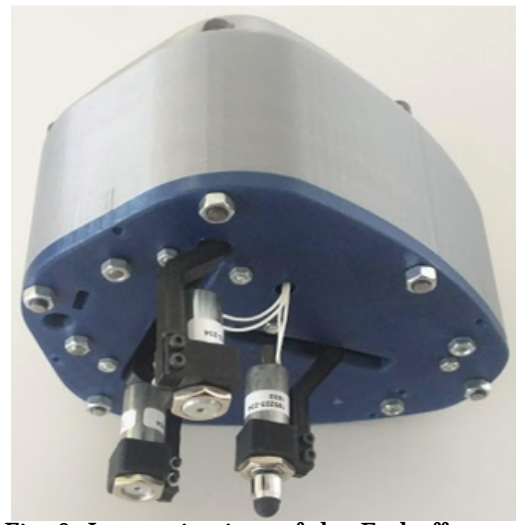

Fig. 9. Isometric view of the End-effector

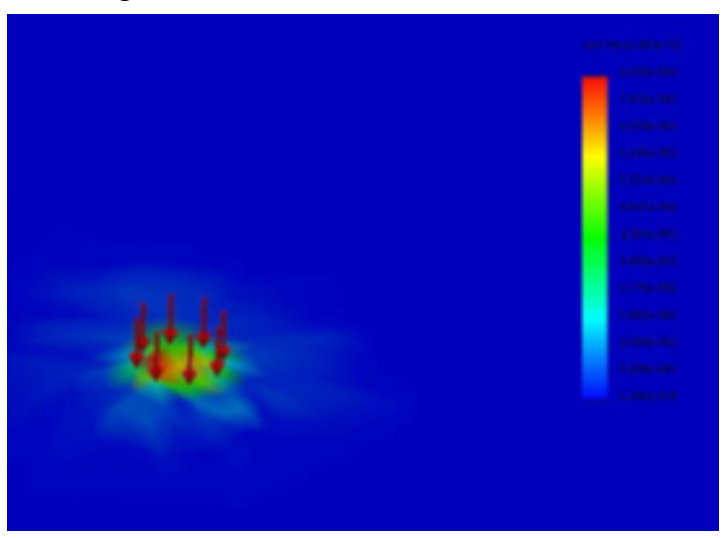

Fig 10. Pressure area of the finger tapping.

the touch screen breaks is $8.32 * 10^{-3}\left(\frac{\mathrm{N}}{\mathrm{m}^{2}}\right)$ so we can conclude from the analysis that the touch screen resists the demands it is subjected to.

\section{Conclusions}

This paper presents a new technology for the electronics industry to provide consumers a better product, touchscreen devices should be tested before being released on the market to avoid selling defective products.

By fused deposition modeling (FDM) technology we have achieved the physical parts of the end effector in a very short time, all parts are made of ABS (AcrylonitrileButadiene-Styrene) material that offers a high mechanical resistance over life time.

The final effector is designed to perform a repeatable and accurate test for a relatively small cost.

In the automotive industry, more interior products contain touch screen so the consumer can enter orders more easily compared to traditional buttons.

\section{References}

1.*** How do touch screens work available at: https: //scienceline.org/ 2012/01/okay-but-how-do-touchscreens-actually-w ork
2.**** Robot end effector available at: https://en.wikipedia.org/wiki/ Robot_end_effector/

3.J ENKININSŌN D. R., AUBURN, WA (US) TOUCH SCREEN TESTING PLATFORM Pub. No.: US 2012/0146956 A1, 2012 Pub. Date: Jun. 14, 2012 4. ANTON, A. A., MUNTEAN, S., SUSAN-RESIGA, R. F., SWIRL2D: ANINTERFACE TRACKING ALGORITHM FOR COMPUTING THE TWODIMENSIONAL SWIRLING FLOWS WITH STAGNANT REGION, Proceedings of ihe Romanian Academy Series A-Mathematics PhysicsTechnical Sciences Information Science, Volume 17, Issue 4, 2016,pp. 366-373

5.ANTON, A. A., CRETU, V., RUPRECHT, A., MUNTEAN, S., TRAFFICREPLAY COMPRESSION (TRC): A HIGHLY EFFICIENT METHOD FORHANDLING PARALLEL NUMERICAL SIMULATION DATA, Proceedingsof ihe Romanian Academy Series A-Mathematics Physics TechnicalSciences Information Science, Volume 14, Issue 4, 2013, pp. 385-392

6.WALKER, G., SENIOR, Touch Technologist Intel Corporation J une 1, 2014 -Fundamentals of Projected-Capacitive Touch Technology 7.***Touch screen gestures available at: https://holliecrooks. wordpress.com /2014/03/11/designing-an-app-touch-screen-gestures/ 8.GHIONEA, I. G., Proiectare Asistata În CATIA V5. Elemente teorietrice si aplicatii, Ed. BREN, 2007

9.*** Capacitive Touch Screen available at: https://www. indiamart.com/proddetail/capacitive-touch-screen-2380794391.html 10.*** Resistive Touch Screen Technology available at:https:// www.touchscreensolutions.com.au/faq-items/resistive-touch-screentechnology/

11.VASILESCU, M. D., FLESER, T., Influence Of Technological Parameters on the Dimension of Gear Parts Generated with PLA Matherial by FDM 3d Printing, Mat. Plast., 55 , no. 2, 2018, p. 247-251 12.STAN, D., TULCAN, A., COSMA, C., THE INDUSTRIAL ENGINEERING PROFILE AND COMPETENCES, Modtech 2010: New Face of TMCR, Proceedings, 2010, p. 543-546

13.COSMA, C., ROTAR, D., CIOANA, C., SERBAN, I., Redesigning Plastic Products, Mat. Plast., 48 , no. 3, 2011, p. 259-262

14.COSMA, C., DUME, A. I., TULCAN, A., ICLANZAN, T., Reverse engineering for injection parts, Mat. Plast., 45 , no. 2, 2008, p. 208-213 15. MARINESCU, M., LARISA BUTU, L., BORDA, C., ARSENE, D., BUTU, M., Comparative Study of Tensile Behaviour forLayered Polymeric Composite Materials, Mat. Plast., 55 , no. 3, 2018, p. 279-285 16.MICU, L.M., LAZAR, I., CIRCIUMARU, A., BORDEASU, I., PIRVULESCU, L.D., HLUSCU, M., New Results Regarding Cavitation Behavior of Polymers Modified with Anorganic Substances Coated on Bronze Surfaces, Mat. Plast., 55 , no. 3, 2018, p. 460-463

17.MITELEA, I., VARZARU, N., BORDEASU, I ., POPESCU, M., The High Frequency Welding Aptitude of Thermoplastic Polymers, Mat. Plast., 46 , no. 1, 2009, p. 101-107

18.TUT, V., TULCAN,A., COSMA, C., SERBAN, I., Application of CAD/ $C A M / F E A$, reverse engineering and rapid prototyping in manufacturing industry. International J ournal of Mechanics , Vol.4, Issue 4, 2010, p.79-86

19.CARUTASU, N. L., SIMION, I., CARUTASU, G., JIGA, G., ARION, A.F., Experimental Test for Elastic and Mechanical Evaluation of ABS Plastic Used in 3D Printing, Mat. Plast. 52, no.3, 2015, p. 398

20.*** Resistive Touch Screen Technology available at: https:// www.touchscreensolutions.com.au/faq-items/resistive-touch-screentechnologyl

21.PASCU, N.E., DOBRESCU, T., POPESCU, A., ADIR, V.G., Fused Deposition Modeling Technology to Redesign a Nylon Component, Mat. Plast. 54, no.1, 2017, p. 168,

22.PASCU, N.E., DOBRESCU, T.G., BALAN, E., JIGA, G., ADIR, V., Design of ABS Plastic Components through FDM Process for the Quick Replacement of Outworn Parts in a Technological Flow, Mat. Plast. 55, no.2, 2018, p. 212

\section{Manuscript received: 12.02 .2019}

